\title{
Is laparoscopic totally extra peritoneal repair of hernia (TEP) superior than trans-abdominal preperitoneal (TAAP) mesh repair of inguinal hernia- our experience from a tertiary care hospital, Kolkata
}

\author{
Ambar Gangopadhyay ${ }^{1}$, Bikash Chandra Ghosh ${ }^{2}$ \\ ${ }^{1,2}$ Associate Professor, Department of General Surgery, R. G. Kar Medical College Kolkata
}

\section{A B S T R A C T}

\begin{abstract}
Background: The most common laparoscopic techniques for inguinal hernia repair are transabdominal preperitoneal (TAPP) repair and totally extraperitoneal (TEP) repair. In TAPP a mesh is placed through peritoneal incision over possible sites of hernia by going into peritoneal cavity, where as in TEP the peritoneal cavity is not entered and a mesh is used to seal the hernia from outside the peritoneum. Aims and Objectives: The aim of the current study was to compare the outcome of Total Extra- peritoneal (TEP) versus Trans-abdominal Pre-peritoneal (TAPP) repair of inguinal hernia, where both can be done. Materials and Methods: The current randomized control study was conducted among eighty patients of inguinal hernia. Of these, the sampling was done through random allocation of patients for TEP (Group-I) and TAPP (Group-II), comprising forty patients in each group. All patients irrespective of group were observed for pain (by VAS Score), mean operative time, duration of hospital stay, days taken to resume their normal activities, intra-operative and early post-operative complications and recurrence if any. Results: The pain in both groups was insignificant until one day but highly significant differences $(p<0.0001)$ were observed by end of day 2 and 1 month, showing higher degree of pain in TAPP with respect to TEP procedure. The differences in mean operative time for surgery was highly significant $(p<0.0001)$ with mean time of $86.72 \mathrm{~min}$ (TAPP) and 99.72 (TEP). The duration of hospital stay was higher in TAPP (5.2 days) compared to TEP ( 2.6 days). The mean time to return to normal activities was 10.8 days (TAPP) and 6.2 days (TEP) which was highly significant $(p<0.0001)$. The recurrence though occurred only in one patient in TEP group which was negligible. The other post-operative complications was seroma ( 8 cases; TAPP) versus ( 1 case; TEP) and it was highly significant $(p<0.0001)$. The port site infection was in 20 $\%$ patients $(8 / 40)$ in TAPP compared to $2.5 \%(1 / 40)$ in TEP group. Conclusion: The TEP is comparatively superior than TAPP procedure in terms of post-operative complications, duration of hospital stay and return to normal activities.
\end{abstract}

Key words: Inguinal hernia; Laparoscopic repair; Comparison of TAPP and TEP

\section{INTRODUCTION}

The only treatment modality for inguinal hernia is surgical repair, which is one of the most common performed surgical procedures adopted worldwide. ${ }^{1}$ In the United
States, inguinal hernioplasty accounts for approximately 800,000 cases yearly. ${ }^{2}$ An inguinal hernia is a weakness of the abdominal cavity, which allows escape of internal organ, especially intestine. ${ }^{3}$ If the bowel strangulates or becomes obstructed, it could be life-threatening. A hernia is usually 
repaired using synthetic mesh either with open surgery or by less invasive laparoscopic techniques. ${ }^{1}$ Commonly adopted procedures are transabdominal perperitoneal (TAPP) repair and totally extra peritoneal (TEP) repair. TEP repair is considered to be more difficult than TAPP. ${ }^{4}$

The EHSG (the European Hernia Society Guidelines) state that Lichtenstein or endoscopic repair should be the procedure of choice for both primary unilateral and bilateral inguinal hernias with the note that endoscopic repair should only be performed by experienced surgeons. ${ }^{5}$

The committee is of the opinion that TEP is preferred to TAPP in the case of endoscopic surgery. Today, surgeons are adopting the recent trends of laparoscopic methodologies as they leave minimal scar after surgery, require smaller incisions, less bleeding, less post-operative infection, less days of hospitalization, minimal pain and faster recovery. The current study was designed to validate the performance of unilateral laparoscopic TEP repair or TAPP repair of inguinal hernias by the experience of a single surgeon at our institution.

\section{Aims and objective}

The objective of this study was to compare the relative advantage of laparoscopic TEP over TAPP for inguinal hernia, in terms of post operative pain (by VAS score), duration of surgery, duration of hospital stay, return to normal activities, intra and post operative complications and recurrence of hernia between the two groups.

\section{MATERIAL AND METHODS}

This randomized control study (superiority trial) was carried out in the Department of Surgery, R.G.Kar Medical College and Hospital from January 2016 to October 2017. All patients admitted in General surgical unit presenting with uncomplicated unilateral inguinal hernias were included in the study. A total of 80 patients, 40 patients underwent TEP repair and 40 patients underwent TAPP repair of inguinal hernias. All cases were males between age group of 30 to 68 years.

The Inclusion criteria were uncomplicated hernia of patients with aged $\geq 18$ years. Exclusion criteria were patients who had acute or obstructed inguino-scrotal hernia, recurrent and bilateral hernia, previous history of midline, paramedian or suprapubic incision, undergone totally extra peritoneal repair to open repair and any cases of recurrent hernia and above all those who were medically unfit for general anesthesia were excluded from the study.

Operative steps and per-operative complications were observed. Follow up was done for a period of six months, following post-operative patients at one week, once in three months and at the end of six months after surgery. At the end of the study comparison between both methods (TEP and TAPP) was done based in terms of post-operative pain (by VAS score), duration of surgeryduration of hospital stay, return to normal activities, intra and post-operative complications and recurrence of hernia between the two groups.

\section{Statistical analysis}

In this study the end point data was analysed by two statistical softwares-Statistical package for the social sciences version 20.0.1 and Graph Pad prism version 5. The categorical data namely; Intra operative and Post-operative complication was analysed by Chi-square test. The Independent sample ' $t$ ' test was used to compared ordinal data namely age, duration of surgery, duration of hospital stay, return to normal activities, intra and post-operative complications and recurrence of hernia between the two groups.

\section{RESULT}

The current study was conducted to establish the advantages and disadvantages of laparoscopic TAPP versus TEP repair of inguinal hernia. Of the forty cases of TAPP, 26/40 cases were right sided hernias with remaining one left sided and 29/40 were indirect and rest were direct hernias. Similarly of the forty cases of TEP, 25/40 cases were right sided hernias with remaining one left sided and 21/40 were indirect and rest were direct hernias. The mean age differences in both groups were statistically insignificant $(\mathrm{p}=0.9906)$ (Table 1). No sex was matched as all cases were males.

\section{Pain scores (by VAS Score)}

The average pain scores (by VAS Score) at different intervals of time post operatively are mentioned in Table 2. It was observed that only significant differences in pain scores (post-operative) in both group was at 2 days and at 1 month and pain subsided within 6 months follow up.

\section{Mean operative time}

The mean operative time in TEP group was 99.72 and in TAPP group was $86.72 \mathrm{~min}$ as mentioned in Table 3. Statistically significant difference of mean operative time in both groups was observed $(\mathrm{p}<0.0001)$.

$\begin{aligned} & \text { Table No. 1: Distribution of mean age in two } \\
& \text { groups* }\end{aligned}$
\begin{tabular}{lcc} 
& \\
\hline & Mean \pm SD & P \\
\hline TEP $(n=40)$ & $50.82 \pm 9.51$ & 0.9906 \\
TAPP $(n=40)$ & $50.85 \pm 9.30$ & \\
\hline *Only male subjects were in both groups
\end{tabular}




\begin{tabular}{|c|c|c|c|}
\hline \multirow{2}{*}{$\begin{array}{l}\text { Different time } \\
\text { intervals } \\
\text { (post surgery) }\end{array}$} & \multicolumn{2}{|c|}{ Mean \pm SD } & \multirow[t]{2}{*}{$P$ value } \\
\hline & TEP $(n=40)$ & $\operatorname{TAPP}(n=40)$ & \\
\hline $24 \mathrm{hrs}$ & $7.6 \pm 0.70$ & $7.9 \pm 0.60$ & $p=0.0662$ \\
\hline 2 days & $4.8 \pm 0.98$ & $6.8 \pm 1.69$ & $p<0.0001$ \\
\hline 1 month & $1.4 \pm 0.50$ & $4.3 \pm 0.96$ & $p<0.0001$ \\
\hline 6 months & $1.0 \pm 0.15$ & $1.1 \pm 0.36$ & $p=0.0486$ \\
\hline
\end{tabular}

\begin{tabular}{lcc}
\multicolumn{3}{l}{ Table No. 3: Comparison of operative time (in } \\
minutes) between TEP and TAPP & P value \\
\hline Type of Operation & $\begin{array}{c}\text { Mean operating time } \\
\text { (mins) } \pm \text { SD }\end{array}$ & \\
\hline $\operatorname{TEP}(n=40)$ & $99.72 \pm 7.36$ & $<0.0001$ \\
$\operatorname{TAPP}(n=40)$ & $86.72 \pm 6.39$ & \\
\hline
\end{tabular}

Duration of hospital stay and return to normal activities The average duration of hospital stay and return to normal activities is depicted in Table 4. The differences among both groups in duration of hospital stay and return to normal activities were highly significant $(\mathrm{p}<0.0001)$. The duration of stay was higher in TAPP was due to increase in pain and port site infection.

\section{Other Post-operative complications}

The post-operative complications observed in the current study is depicted in Table 5. We observed recurrence of hernia only in one patient TEP group and it was not statistically significant $(p=0.31426)$. Similarly haematoma occurred in 1/40 cases in TAPP and 9/40 cases in TEP and the differences was statistically significant $(p=0.0068)$. Occurrence of seroma was observed in 8/40 cases of TAPP but only one case in TEP which was also statistically significant $(\mathrm{p}=0.01325)$. Port site infection occurred in $8(20 \%)$ cases in TAPP and $1(2.5 \%)$ cases in TEP group. All infections were cured by another course of antibiotics for 10 days. Association between wound infection in two groups was statistically significant $(p<0.0001)$. There is no mesh infection in any group.

\section{DISCUSSION}

Age

The current study was conducted to compare the laparoscopic procedures (Totally Extra Peritoneal; TEP versus Trans-abdominal Preperitoneal; TAAP) mesh repair in inguinal hernia. The patients included in the study had the age ranging from thirty years to sixty years with a mean \pm SD of $50.82 \pm 9.51$ years in TEP group and $50.85 \pm 9.30$ years in TAPP group. The difference in age between the two groups were not statistically significant $(p=0.9906)$. In a randomized comparative study between
Table No. 4: Comparison of hospital stay and return to normal activity (in days)

\begin{tabular}{llcl}
\hline Parameters & \multicolumn{2}{c}{ Mean \pm SD } & P value \\
\cline { 2 - 3 } & TEP $(\boldsymbol{n}=\mathbf{4 0})$ & $\operatorname{TAPP}(\boldsymbol{n}=\mathbf{4 0})$ & \\
\hline $\begin{array}{l}\text { Post-Operative } \\
\text { hospital stay (days) }\end{array}$ & $2.62 \pm 0.70$ & $5.27 \pm 0.93$ & $<0.0001$ \\
$\begin{array}{l}\text { Return to Normal } \\
\text { Activity (days) }\end{array}$ & $6.21 \pm 0.85$ & $10.87 \pm 1.41$ & $<0.0001$ \\
\hline
\end{tabular}

\begin{tabular}{|c|c|c|c|}
\hline $\begin{array}{l}\text { Post-Operative } \\
\text { complications }\end{array}$ & TEP $(n=40)$ & $\operatorname{TAPP}(n=40)$ & $P$ value \\
\hline Recurrence of hernia & $1(2.5 \%)$ & - & $\mathrm{P}=0.3142$ \\
\hline Heamatoma & $9(22.5 \%)$ & $1(2.5 \%)$ & $P=0.0068$ \\
\hline Seroma & $1(2.5 \%)$ & $8(20 \%)$ & $p=0.0132$ \\
\hline Port site infection & $1(2.5 \%)$ & $8(20 \%)$ & $\mathrm{P}<0.0001$ \\
\hline
\end{tabular}

laparoscopic TEP versus TAPP approach in inguinal hernia conducted in Egypt, ${ }^{6}$ the mean age of the patients was $47.8 \pm 10.4$ years and their age ranged from 19-65 years, however the differences was not significant, as observed in the current study. In yet another prospective randomized trial conducted in New Delhi, ${ }^{7}$ India, the age of the patients were above 18 years but below 70 years and the median age in both groups was 52 years.

\section{Pain (by Vas Score)}

The current study measured the pain scores (by VAS Score) in post- operative patients at 1 day, 2 days, 1 month and at 6 months intervals. The average pain scores at 2 days and 1 month were significantly higher $(\mathrm{p}<0.0001)$ in TAPP compared to TEP, though the differences were not significant at 24 hours and at 6 months follow up in the current study. In a prospective randomized trial conducted by Sharma et al, ${ }^{7}$ the pain scores were analyzed at $8,16,24,32,40$ and 48 hours in the follow up period of one month. Their study did not observe any significant differences in pain scores among both groups until 48 hours post- surgery, though the post- operative pain scores were less in TAPP compared to TEP group at all levels ( 8 hours to 48 hours), but in the current study we observed a significant difference in pain scores 2 days and it is not in agreement with the above mentioned study. In another randomized control trial conducted by Nawaz et $\mathrm{al}^{8}$ from Pakistan, among 120 patients, comprising 60 patients in TEP and 60 patients in TAPP group, observed mild pain in 40/60 patients in TEP group and 25/60 patients in TAPP group in their one year follow up study. In yet another randomized control trial study on the similar line conducted by Wei et al, from China with a total of 1047 patients, did not observe any significant differences in pain scores among both groups. Another study conducted by Kockering et al, ${ }^{10}$ from Germany in four years follow 
up, comprising of 2246 patients, of which 1464 patients in TAPP and 782 patients in TEP group, did not find any significant difference between both groups in terms of pain scores. So from the above studies, it is clear the pain persists in both TEP and TAPP procedures, but the duration might differ as it depends on the experienced surgeons following the procedures.

\section{Duration of surgery}

The mean operative time in the current study was $99.72 \mathrm{~min}$ in TEP group and $86.72 \mathrm{~min}$ in TAPP group and there was statistically significant difference in the mean operative time in both groups $(p<0.0001)$. In a prospective randomized trial conducted by Sharma et al, ${ }^{7}$ among 60 patients (30; TEP and 30; TAPP) the overall operating time was $114.31 \pm 24.06 \mathrm{~min}$ in both groups, however the mean operating time was $120.89 \pm 29.28 \mathrm{~min}$ (75-190 $\mathrm{min}$ ) in TEP compared to $108.16 \pm 16.10 \mathrm{~min}$ (65-135 min) in TAPP group but the differences among groups were insignificant $(p=0.117)$. So it is understood that TEP procedure takes more operative time when compared to TAPP procedures. In another randomized control trial conducted among 120 patients (60 TEP; 60 TAPP), the mean operating time was $45.1 \pm 3.54 \mathrm{~min}$ in TEP compared to $70 \pm 6.01 \mathrm{~min}$ in TAPP group and the differences among groups were highly significant $(\mathrm{p}<0.0001) .{ }^{8}$ In yet another prospective randomized comparative study conducted by Elhendawy et al, ${ }^{6}$ the operative time was $151.7 \pm 24.8$ in TAPP approach in comparison to $88.42 \pm 30.6$ minutes in TEP approach. In the above two studies, the operative time was higher in TAPP procedure which is not in good agreement with the findings of our study as we observed more operative time in TEP rather than TAPP.

Duration of hospital stay and return to normal activities The differences in the average duration of hospital stay and return to normal activities observed in the current study was highly significant $(\mathrm{p}<0.0001)$ and we observed less hospital stay (2.62 days; TEP) and early return to normal activities (6.21 days; TEP) when compared to TAPP group. In a prospective randomized trial conducted by Sharma et al, ${ }^{7}$ the average duration of hospital stay was 52.29 hours in TEP group when compared to 52 hours in TAPP group but the differences in hospital stay in both groups were insignificant $(p=0.427)$. Similarly the average days to return to normal activities was lower in TAPP with 11.8 days when compared with TEP which was of 12.41 days. This observation is contradictory to what we observed in the current study. In another study reported from Pakistan ${ }^{8}$ observed only one day stay in hospital after surgery in both groups and the average days taken to return to normal activities was four days in TEP and five days in
TAPP which to some extent is in similarity with our study as we also observed less days to return to normal activities in TEP group.

In another randomized control trial study from China ${ }^{9}$ with a total of 1047 patients, did not observe any significant differences in terms of duration of hospital stay and return to normal activities in both groups. This observation does not conform to most of the study reported in similar parameters.

\section{Other post-operative complications}

In the current study, the post-operative complications viz, recurrence of hernia was observed only in one patient in TEP group and it was not statistically significant $(p=0.31426)$. Similarly haematoma occurred $1 / 40$ cases in TAPP and 9/40 cases in TEP and the differences were statistically significant $(\mathrm{p}=0.0068)$. The occurrence of seroma was observed in 8/40 cases of TAPP but only one case in TEP which was also statistically significant $(\mathrm{p}=0.01325)$. Port site infection occurred in $8(20 \%)$ cases in TAPP and $1(2.5 \%)$ cases in TEP group. Association between wound infection in two groups was statistically significant $(p<0.0001)$. There was no mesh infection in any of the group.

In a prospective randomized trial conducted by Sharma et al, ${ }^{7}$ on 60 patients, their study noted seroma in $2 / 30$ patients in TAPP group and 4/30 patients in TEP group, though the difference was insignificant $(\mathrm{p}=0.431)$. Subcutaneous emphysema was more commonly noted in the Group II (TEP) (p-value 0.038). These findings do not match with the findings of our study.

In another randomized comparative study comprising of 30 patients from Eqypt, their study observed postoperative scrotal edema in $9 / 15$ cases in TAPP approach in comparison to TEP approach (3/15 cases). Postoperative Hematoma and ileus were higher in TAPP technique (2/15 cases). Postoperative Surgical emphysema was higher in TEP technique ( $3 / 15$ cases). These complications were not similar to the complications which were observed in our study.

In yet another randomized control trial conducted by Nawaz et $\mathrm{al}^{8}$ from Pakistan, among 120 patients, comprising 60 patients in TEP and 60 patients in TAPP group, one patient in TAPP group developed port site infection in TAPP group but none in TEP group. No recurrence of hernia was observed in one year follow up and none developed deep site infection in both group. These findings are more or less similar to our study, as we also found higher port-site infection in TAPP group compared to TEP group. 
In another randomized control trial study on the similar line conducted by Wei et al, ${ }^{9}$ from China with a total of 1047 patients, did not observe any significant differences in post-operative complications among both groups. Similar findings were also observed in another study conducted by Kockering et al, ${ }^{10}$ did not find any significant difference between both groups in terms of any complications. The findings of the above two studies are not is agreement with our study.

In another retrospective study which included 90 cases reported by Varcus et al, ${ }^{11}$ based on the primary outcome of recurrence of hernia and secondary outcome of short and long term complications, including hernia, seroma, inflammation of testis, chronic inguinal pain in 2 years follow up, Regarding the main outcome there was no recurrence of the hernia, which is similar to the findings of the current study. The other complications were two cases of bleeding in the TAPP group; both were managed by laparoscopic sealing of the damaged vessels, 8 cases of post-operative edema of testis in TAPP and 3 cases in TEP. Regarding the subcutaneous emphysema there were 16 cases in TAPP and 3 cases in TEP. These complications were not observed in the current study. So from the above studies, it is understood that the post-operative complications varies in terms of individual case to case and variations do occurs in both procedures.

\section{CONCLUSION}

Taking in consideration of the parameters used for assessment of laparoscopic procedure in both groups, our study is more in favor of TEP than TAPP procedure in repair of inguinal hernia.

\section{ACKNOWLEDGEMENT}

Post-graduate Trainees and all staffs of Department of Surgery, R.G.Kar Medical College, Kolkata.

\section{REFERENCES}

1. International guidelines for groin hernia management.The HerniaSurge Group.Hernia 2018; 22(1): 1-165.

2. Berndsen MR, Gudbjartsson $T$ and Berndsen $F H$. Is a Technically Challenging Procedure More Likely to Fail? A Prospective Single-Center Study on the Short- and LongTerm Outcomes of Inguinal Hernia Repair. Surg Res Pract 2018;2018:7850671.

3. Ayush, Rajeev and Singh L. A Comparative study in Laparoscopic inguinal hernia repair between fixation and non-fixation of Mesh. Journal of Evidence Based Medicine and Healthcare 2016; 3(14): 490-492.

4. Wake BL, McCormack K, Fraser C, Vale L, Perez J and Grant A. Transabdominal pre-peritoneal (TAPP) vs totally extraperitoneal (TEP) laparoscopic techniques for inguinal hernia repair. Cochrane Database of Systematic Reviews 2005, Issue 1. Art. No.: CD004703.

5. Simons MP, Aufenacker T, Bay-Nielsen M, Bouillot JL, Campanelli G, Conze J, et al. European Hernia Society guidelines on the treatment of inguinal hernia in adult patients. Hernia 2009; 13(4):343-403.

6. Elhendawy $\mathrm{AO}, \mathrm{Abd}-\mathrm{Raboh} \mathrm{OH}$, Ismail TA and Nagy AA. Randomized Comparative Study Between Laparoscopic Transabdominal Pre-Peritoneal Versus Totally Extraperitoneal Approach in Inguinal Hernia Repair. Advances in Surgical Sciences 2018; 6(1):1-6.

7. Sharma D, Yadav K, Hazrah P, Borgharia S, Lal R and Thomas S. Prospective randomized trial comparing laparoscopic transabdominalpreperitoneal (TAPP) and laparoscopic totally extra peritoneal (TEP) approach for bilateral inguinal hernias. Int J Surg 2015; 22:110-117.

8. Nawaz T, Ayub MW, Murad F, Ali Q, Khan A and Anwar I. Comparison of Laparoscopic Total Extra Peritoneal (TEP) Techniques versus Transabdominal Preperitoneal (TAPP) Technique for Inguinal Hernia Repair. Journal of Rawalpindi Medical College (JRMC) 2015; 19(3):220-222.

9. Wei FX, Zhang YC, Han W, Zhang YL, Shao $Y$ and Ni R. Transabdominal Preperitoneal (TAPP) Versus Totally Extraperitoneal (TEP) for Laparoscopic Hernia Repair: A Meta-Analysis. Surg Laparosc Endosc Percutan Tech 2015; 25(5):375-383.

10. Köckerling F, Bittner R, Kuthe A, Hukauf M, Mayer F, Fortelny R, et al. TEP or TAPP for recurrent inguinal hernia repairregister based comparison of the outcome. Surg Endosc 2017; 31:3872-3882.

11. Vărcuş F, Duță C, Dobrescu A, Lazăr F, Papurica M and Tarta C. Laparoscopic Repair of Inguinal Hernia TEP versus TAPP. Chirurgia (Bucur) 2016; 111(4):308-312.

\footnotetext{
Authors Contribution:

AG-Concept and design of the study, manuscript preparation, statistical analysis and interpretation, critical revision of manuscript, collection of data;

BCG- Reviewed literature and assistance in preparing first draft of manuscript, data collection.

Work attributed to:

Department of General Surgery, R.G.Kar Medical College, Kolkata.

Orcid ID:

Dr. Ambar Gangopadhyay- (1) http://orcid.org/0000-0003-2160-9256

Dr. Bikash Chandra Ghosh- (1) http://orcid.org/0000-0001-5708-9243

Source of Support: R.G.Kar Medical College, Kolkata.(All surgeries conducted in this Government Medical College)., Conflict of Interest: None.
} 